\title{
(5)

\section{En mann i 50-årene med feber og hevelse på halsen}

NOE Å LAERE AV

\section{BENTE JANNESTAD}

E-post: uxjabb@sthf.no Akutt- og beredskapsklinikken Sykehuset Telemark, Skien Bente Jannestad er lege i spesialisering i anestesiologi. Forfatteren har fylt ut ICMJE-skjemaet og oppgir ingen interessekonflikter.

\section{HILDE KRISTIN SKUDAL}

Medisinsk klinikk

Sykehuset Telemark, Skien

Hilde Kristin Skudal er spesialist i indremedisin og i infeksjonssykdommer og overlege.

Forfatteren har fylt ut ICMJE-skjemaet og oppgir ingen interessekonflikter.

\section{ANNIKA JØNTVEDT BOCK}

Akutt- og beredskapsklinikken

Sykehuset Telemark, Skien

Annika Jøntvedt Bock er lege i spesialisering i anestesiologi.

Forfatteren har fylt ut ICMJE-skjemaet og oppgir ingen interessekonflikter.

\section{MORITZ BØHME}

Radiologisk avdeling

Sykehuset Telemark, Skien

Moritz Bøhme er spesialist i radiologi og overlege.

Forfatteren har fylt ut ICMJE-skjemaet og oppgir ingen interessekonflikter.

\section{TORKJELL NØSTDAHL}

Akutt- og beredskapsklinikken

Sykehuset Telemark, Skien

Torkjell Nøstdahl er spesialist i anestesi og overlege.

Forfatteren har fylt ut ICMJE-skjemaet og oppgir ingen interessekonflikter.

En middelaldrende mann ble innlagt på sykehus med mistanke om sepsis. Han hadde nylig gjennomgått et lengre sykeleie med behov for intensivbehandling og var blitt utskrevet tre dager før den aktuelle innleggelsen. Under utredningen ble det etter hvert gjort et uventet funn ved ultralydundersøkelse.

En mann i 50-årene, som i hovedsak var frisk tidligere, fikk diagnostisert diffust storcellet Bcellelymfom. Han hadde tumorvev i duodenum, noe som medførte perforasjonsfare. For å avlaste tarmen var det nødvendig å gi parenteral ernæring, og to måneder etter at han ble diagnostisert, ble det av den grunn lagt en tunnelert veneport i venstre vena jugularis 
interna. Pasienten gjennomgikk kjemoterapi med syklofosfamid, doksorubicin, vinkristin og prednisolon kombinert med rituksimab (såkalt R-CHOP-kur) cirka tre måneder etter diagnosetidspunktet. Strålebehandling var planlagt mot resttumor, men ble utsatt, da pasienten utviklet tynntarmsileus. Han hadde et tumorkonglomerat som vokste inn i krøset fra bakre bukvegg og innbefattet tynntarm. Det ble gjennomført akutt operasjon med bypass av tumorkonglomeratet og anleggelse av en side-til-side-anastomose. Det ble et komplisert sykdomsforløp med flere reoperasjoner på grunn av anastomoselekkasje, sårruptur og sepsis med multiorgansvikt. I løpet av to uker ble pasienten operert og reoperert til sammen fire ganger før man ved siste operasjon anla en endejejunostomi og en mukokutan kolonfistel. Under forløpet hadde han behov for respiratorbehandling og kontinuerlig dialyse grunnet akutt nyresvikt. Det ble lagt inn et sentralt venekateter med fem lumen i høyre v. jugularis interna. Veneporten på venstre side var ikke i bruk. Etter en uke var nyrefunksjonen tilfredsstillende, og dialysen ble avviklet. Etter tre ukers behandling på intensivavdelingen ved lokalsykehuset ble pasienten overflyttet til regionsykehus for fornyet vurdering. Her fallerte han igjen respiratorisk. Han ble intubert og behandlet til sammen 15 dager på respirator. Det ble utført flere undersøkelser, deriblant ny CT, som viste et vaskelokulament i øvre høyre abdominalkvadrant. Dette ble behandlet med ultralydveiledet perkutan drenasje. CT påviste også en dyp venetrombose i høyre v. iliaca communis. Pasienten fikk derfor terapeutisk behandling med dalteparin (Fragmin, $100 \mathrm{IE} / \mathrm{kg} \times 2$ ). Etter 15 dager på intensivavdelingen ble pasienten overflyttet til sengepost før han, etter til sammen tre uker ved regionsykehuset, ble flyttet tilbake til sengepost ved lokalsykehuset.

Som et resultat av flere tarmreseksjoner utviklet pasienten de neste ukene kort tarmsyndrom. På det meste kom det opptil tolv liter på stomien daglig. Han spiste selv normal kost og hadde god matlyst, men grunnet rask passasje gjennom tarmen fikk han ikke i tilstrekkelig grad nyttiggjort seg maten han spiste. Han ble vurdert av ernæringsfysiolog, og det ble supplert med parenteral ernæring og intravenøs væske. Elektrolytter og væskeregnskap ble kontrollert daglig. Det sentrale venekatetret ble autoseponert etter å ha ligget inne i cirka syv uker. På sengeposten ble derfor veneporten tatt i bruk igjen, fire måneder etter at den var anlagt, og to måneder etter at den sist var i bruk. Man fikk ikke aspirert blod fra veneporten, men væske kunne infunderes uten problemer. Pasienten hadde ingen smerte eller hevelse rundt veneporten eller langs det subkutane kateterforløpet. Røntgen thorax viste uendret posisjon av katetret. Veneporten ble brukt uproblematisk til både væske og parenteral ernæring i fire uker.

De vanligste komplikasjonene ved inneliggende intravasale katetre er trombedannelse, infeksjon og utvikling av fibrinhylse (1).

Vi vurderte at vansker med å aspirere blod fra veneporten kunne skyldes en fibrinhylse rundt kateterspissen. En fibrinhylse kan omslutte katetret og strekke seg forbi den distale åpningen. Dette kan virke som en enveisventil og gi problemer med aspirasjon eller gi $ø$ kt motstand ved injisering av væske (1).

Etter totalt tre måneders sykehusopphold ble pasienten skrevet ut til hjemmet. Han hadde fortsatt behov for parenteral erncering og intravenøst vecsketilskudd. Døgnproduksjon på stomien var nå redusert til mellom 2,5 og 6 liter, og behovet for parenteral erncering var redusert. Etter utreise var det planlagt ukentlige kontroller av elektrolytter hos fastlege, og på grunn av den beskrevne venetrombosen ble terapeutisk behandling med dalteparin $100 \mathrm{IE} / \mathrm{kg} \times 2$ opprettholdt.

Andre dag etter utskrivelsen fikk pasienten smerter på venstre side av halsen. Hans kone observerte diffus hevelse i det smertefulle området ved infusjon av parenteral ernæring. Neste dag fikk pasienten feber og frostrier, og han ble innlagt på sykehus med mistanke om sepsis. Ved undersøkelse i akuttmottaket var han medtatt, men våken, klar og orientert. Han hadde en pulsfrekvens på $135 \mathrm{slag} / \mathrm{min}$, temperatur på $40,1^{\circ} \mathrm{C}$ og respirasjonsfrekvens på 25 pust/min. Blodtrykket ble målt til 137/83 mm Hg. Blodprøver viste CRP $253 \mathrm{mg} / \mathrm{l}$ (referanseområde $<5 \mathrm{mg} / \mathrm{l}$ ) og leukocytter $2,9 \cdot 10^{9} / \mathrm{l}\left(3,5-10 \cdot 10^{9} / \mathrm{l}\right)$. Dermed falt han, med mistenkt infeksjon og fire av fire kriterier for systemisk inflammatorisk responssyndrom (SIRS) oppfylt, innenfor den gamle definisjonen av sepsis. 
Diagnosen SIRS stilles dersom to eller flere av følgende fire kriterier er oppfylt: temperatur over $38^{\circ} \mathrm{C}$ eller under $36{ }^{\circ} \mathrm{C}$, pulsfrekvens over 90 slag/min, respirasjonsfrekvens over 20 pust $/$ min eller $\mathrm{PaCO}_{2}$ under $4,3 \mathrm{kPa}$, leukocytter over $12 \cdot 10^{9} / \mathrm{l}$ eller under $4 \cdot 10^{9} / \mathrm{l}$ eller over $10 \%$ umodne nøytrofile granulocytter. Sepsis ble tidligere definert som SIRS pluss infeksjon (2).

Pasienten var tydelig hoven og palpasjonsøm på venstre side av halsen, huden var reaksjonsløs, og det var ingen rubor over hevelsen. Røntgen thorax viste ingen aktuelle forandringer, og urinstiks var negativ. Grunnet ovennevnte symptomer lokalisert over stedet for inneliggende veneport mistenkte man en kateterassosiert infeksjon. Det ble sikret blod til blodkulturer før man startet antibiotikabehandling med kloksacillin $2 \mathrm{~g} \times 4$ og tobramycin $400 \mathrm{mg} \times 1$. Man fikk ikke aspirert blod fra veneporten, slik at det ved innkomst kun ble tatt prøver til blodkultur fra perifer vene. Pasienten ble også undersøkt med ultralyd av halsen, uten funn av abscessutvikling.

Ved mistenkt kateterinfeksjon bør det tas blod til blodkulturer både fra katetret og fra perifer vene før oppstart med antibiotika for å sikre adekvat diagnostikk (3).

På grunn av sepsissymptomene ble pasienten lagt til observasjon på intensivavdelingen. Han var sirkulatorisk og respiratorisk stabil uten behov for vasopressor eller respirasjonsstøtte.

Ifølge nasjonale retningslinjer for antibiotikabruk i sykehus er standardbehandlingen for sepsis med utgangspunkt i intravasale katetre kloksacillin $2 \mathrm{~g} \times 4$ intraven $ø$ st og gentamicin 5-7 mg/kg $\times 1$ intravenøst (4). Ved mistanke om sepsis skal antibiotika "gis så snart som mulig og helst innen en time etter innleggelse, men fortrinnsvis etter at blodkultur er sikret. Hver times forsinkelse i oppstart av effektiv behandling er vist å øke mortalitet med ca. $7 \%$ \%).

Ultralydundersøkelsen av halsen viste imidlertid en betydelig trombemasse som nærmest totalokkluderte venstre v. jugularis interna og v. subclavia (figur 1 og 2). Den totale utbredelsen av tromben kunne ikke fremstilles med ultralyd, og det ble derfor supplert med en CT-venografi, som viste utbredt trombosering som omfattet nedre del av venstre v. jugularis (fra nivå med carotisbifurkaturen), v. subclavia og v. brachiocephalica frem til innløpet av v. cava superior (figur 3). Det var multiple luftbobler fordelt i trombemassen. Vi mistenkte at dette var forårsaket av bakterier, og dermed at en infisert trombe var fokus for pasientens infeksjon.



Figur 1 Ultralydfremstilling av ncermest totalokkluderende trombe i venstre vena jugularis interna, longitudinelt snitt. Til venstre for trombemassen (pil D) sees fri lumen (pil A). Pil B og C indikerer luftbobler. 


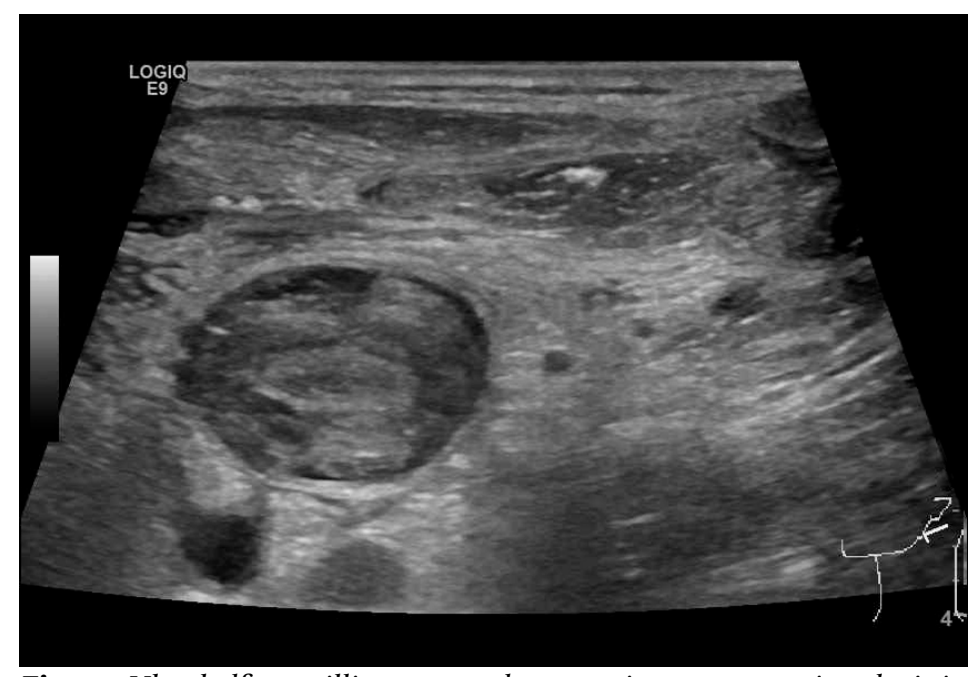

Figur 2 Ultralydfremstilling av trombemasse i venstre vena jugularis interna, tverrsnitt.

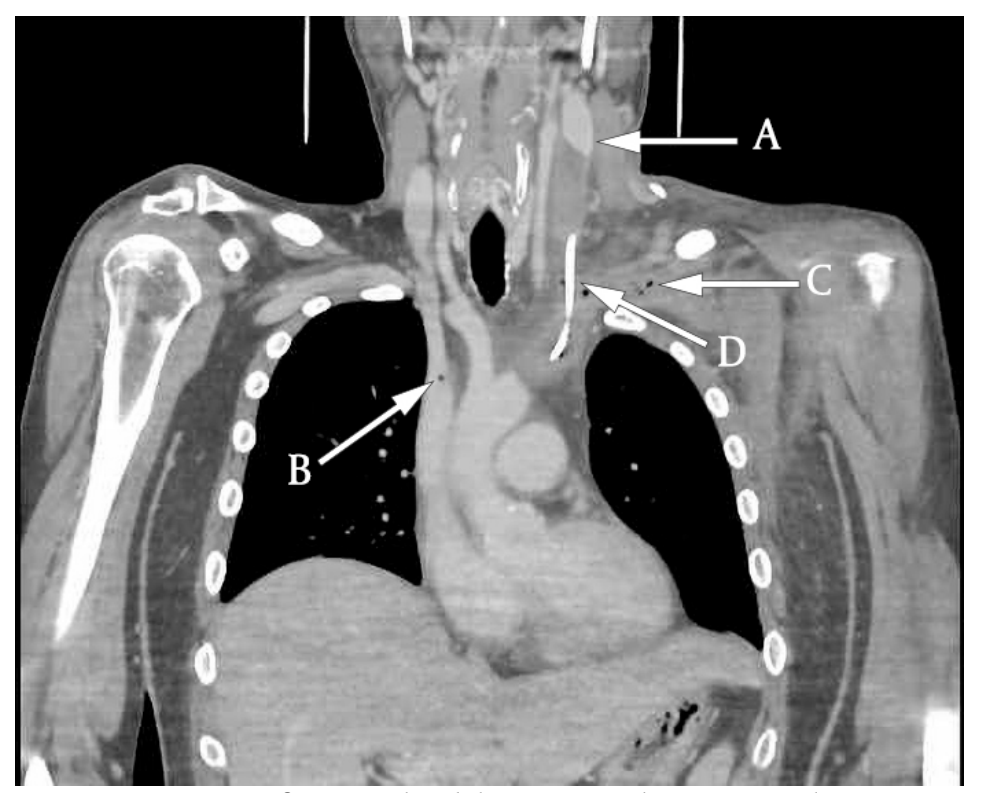

Figur 3 CT-venografi viser utbredelsen av trombemassen. Pil A viser overgangen mellom fri lumen og trombemasse $i$ venstre vena jugularis interna. Pil B viser luft $i$ trombemasse som strekker seg inn $i$ vena cava superior. Pil C indikerer luftbobler i trombemassen $i$ venstre vena subclavia og rundt katetret. Pil D viser katetret. Bemerk også hevelse på venstre side i nakke- og halsregionen.

Ultralyd er en ikke-invasiv og kostnadseffektiv metode for å påvise trombemasser. Dessverre er den suboptimal for diagnostikk av tromber lokalisert dypt under mandibula eller clavicula. CT-venografi er derfor av mange anbefalt som foretrukket undersøkelsesmetode (6). I vårt tilfelle fikk vi med CT-venografi identifisert hele utbredelsen av trombemassen samt påvist karakteristiske luftbobler som underbygget mistanken om infisert trombe.

Funn av små intravenøse luftbobler på CT er ikke unormalt, da små luftbobler kan bli injisert sammen med kontrastvæsken. Luftbobler kan også sees i det mesenterielle eller portalvenøse systemet grunnet iskemi eller infeksjon. Luftbobler inne i en trombemasse er derimot sjeldent, og funnet forsterker derfor mistanken om infisert trombe (7).

Både infeksjon og trombedannelse er vanlige senkomplikasjoner ved intravasale katetre. De vanligste komplikasjonene er listet opp i ramme 1 (8).

\section{Ramme 1 Komplikasjoner ved bruk av sentralt venekateter (8)}

AKUTTE KOMPLIKASJONER

Arytmi 
Blødning

Feilplassering av katetret

Luftemboli

Pneumothorax eller hemothorax

Punksjon av arterie

Skade på ductus thoracicus (ved tilgang via venstre v. subclavia eller venstre v. jugularis interna)

SENKOMPLIKASJONER

Infeksjon

Migrering av katetret

Myokardperforasjon

Nerveskade

Trombose

Intravasale katetre kan forårsake traume mot endotelet og inflammasjon som kan føre til venøs trombedannelse. $70-80 \%$ av tromber i overfladiske eller dype vener på overekstremitetene er forårsaket av intravasale katetre (9-11).

Insidensen av trombedannelse assosiert med sentrale venekatetre er opptil $66 \%$, men i de fleste tilfeller har dette liten klinisk betydning. En sjelden, men alvorlig komplikasjon er infeksjon i en kateterassosiert trombe. Dette forekommer i 7-16\% av tilfellene (12).

Blodbaneinfeksjoner forårsaket av intravasale katetre er en viktig årsak til både morbiditet og mortalitet verden over. Insidensen er synkende, mye på grunn av økt fokus og forebyggende kampanjer. For eksempel har andelen kateterassosierte blodbaneinfeksjoner hos intensivpasienter i USA falt fra 3,64 til 1,65 infeksjoner per 1 ooo sentrale venekatetre i perioden 2001-2009 (13). Den samme trenden ser vi i tall fra Canada (14).

Veneporten ble fjernet uten problemer påfølgende dag, og det ble da observert en tynn, gulbrun film som omsluttet katetret. Kateterspissen ble sendt til dyrkning. En halvtime etter fjerning av katetret ble pasienten igjen forbigående høyfebril, takykard med pulsfrekvens på $138 \mathrm{slag} / \mathrm{min}$ og takypneisk med en respirasjonsfrekvens på 32 pust/min. Vi mistenkte en ny bakteriemi grunnet manipulering av den infiserte tromben. Pasienten fikk intravenøs væske, og symptomene roet seg uten behov for ytterligere tiltak. Vi vurderte ham adekvat dekket med det pågående antibiotikaregimet med kloksacillin og tobramycin, og gjorde derfor på dette tidspunktet ingen endringer i antibiotikabehandlingen.

CT-bildene ble vurdert av karkirurg, som anbefalte å fortsette konservativ behandling med antibiotika samt terapeutisk dose med lavmolekylært heparin (dalteparin) i tre måneder og deretter perorale antikoagulantia i form av enten warfarin eller direktevirkende perorale antikoagulantia (DOAK). I vårt tilfelle kontinuerte vi dalteparin $100 \mathrm{IE} / \mathrm{kg} \times 2$ ut over de første tre månedene, da vi på grunn av pasientens kort tarm-syndrom var usikre på om absorpsjonen av perorale medikamenter var tilstrekkelig god.

Dyrkning av katetret og seks av seks blodkulturer viste vekst av Staphylococcus epidermidis, sensitiv for vankomycin, fusidin, kloramfenikol, tetracyklin og linezolid. Pasienten ble behandlet videre med vankomycin, initialt $1 \mathrm{~g} \times 2$ intraven $ø$ st, deretter dosert etter serumkonsentrasjonen av vankomycin.

Infeksjon assosiert med sentrale venekatetre kan tilskrives fire hovedkilder: kolonisering fra hud, intraluminal kontaminering av katetret (via håndtering av koblinger, korker etc.), hematogen spredning fra annet infeksjonsfokus i kroppen, og kontaminert infusjonsvæske. Kolonisering fra hud er den vanligste årsaken; cirka $65 \%$ av kateterassosierte infeksjoner er forårsaket av dette. Intraluminal kontaminering er også en hyppig årsak og står for cirka $30 \%$ av infeksjonene, spesielt ved kirurgisk implanterte katetre eller katetre som er inneliggende i mer enn to uker (15).

Staphylococcus epidermidis er en grampositiv bakterie som er en del av den normale 
hudfloraen. Den er vanligvis ikke patogen, men kan forårsake infeksjon hos pasienter med risikofaktorer som redusert immunforsvar og inneliggende fremmedlegeme (protese, pacemaker, intravasalt kateter etc.). Bakterien er kjent for å lage biofilm som kan gro på implantert utstyr, og er den vanligste årsaken til infeksjoner relatert til implantert medisinsk materiale (16). Den gulbrune filmen vi så ved fjerning av katetret, var sannsynligvis bakteriefilm misfarget av tromben.

Systemisk behandling med antibiotika er standardbehandling ved infeksjoner relatert til implantert medisinsk utstyr. Slike infeksjoner kan imidlertid være vanskelige å behandle på grunn av dannelse av biofilm. Biofilm kan forhindre effekten av antibiotika, og fjerning av katetret er ofte nødvendig for en vellykket behandling (16).

Etter 16 dager på sykehus ble pasienten skrevet ut til hjemmet.

\section{Diskusjon}

Hos vår pasient mistenkte vi raskt at veneporten kunne være fokus for infeksjon, da han hadde tydelige lokale symptomer. Imidlertid kan symptomene hos immunsupprimerte pasienter være mer subtile og dermed vanskeligere å oppdage. Lokale tegn på infeksjon kan være fraværende grunnet leukopeni, men smerte ved palpasjon angis likevel ofte (17).

Vi kan ikke med sikkerhet fastslå når i forløpet trombemassene utviklet seg hos vår pasient. Vi vet at han under intensivbehandlingen for sin ileusrelaterte sepsis fikk påvist dyp venetrombose i høyre v. iliaca communis. Mest sannsynlig ble også trombene ved veneportkatetret utviklet rundt dette tidspunktet. Det er mindre sannsynlig at de ble dannet senere under pågående terapeutisk behandling med dalteparin, selv om pasienten hadde forhøyet tromboserisiko som følge av underliggende malignitet. Da veneporten igjen ble tatt i bruk til væske og parenteral ernæring på sengepost, fikk vi ikke aspirert blod, men kunne lett injisere væske. Hadde vi her tatt ultralyd av karet, kunne vi kanskje sett trombemasse i venen, og ikke en fibrinhylse, som vi antok var årsaken til aspirasjonsproblemene.

Når i forløpet dette har gått fra å være en ukomplisert trombe til å bli en infeksiøs trombe, vet vi heller ikke. Vi antar at mest sannsynlige rute for kontaminering er intraluminal kontaminering, grunnet daglig bruk av veneport til parenteral ernæring.

I forbindelse med denne kasuistikken har vi gjennomgått våre egne retningslinjer. Vi legger nå til et avsnitt om at man bør vise spesiell årvåkenhet ved oppstått dyp venetrombose og vurdere utvidet diagnostikk knyttet til katetret, samt at man ved septikemi bør vurdere fjerning av veneport.

\section{Konklusjon}

Med denne kasuistikken ønsker vi å belyse komplikasjoner relatert til sentrale venekatetre. Inneliggende katetre utgjør en risiko for trombosering samt en risiko for kolonisering hos pasienter med bakteriemi. Vi ønsker også å rette søkelyset mot infisert trombe som årsak til infeksjon. Vi håper artikkelen kan bidra til økt årvåkenhet for pasienter med særskilt risiko for disse komplikasjonene.

LITTERATUR:

1. Chang DH, Mammadov K, Hickethier T et al. Fibrin sheaths in central venous port catheters: treatment with low-dose, single injection of urokinase on an outpatient basis. Ther Clin Risk Manag 2017; 13: 111-5. [PubMed][CrossRef]

2. Bone RC, Balk RA, Cerra FB et al. Definitions for sepsis and organ failure and guidelines for the use of innovative therapies in sepsis. Chest 1992; 101:1644-55. [PubMed][CrossRef]

3. Mermel LA, Allon M, Bouza E et al. Clinical practice guidelines for the diagnosis and management of intravascular catheter-related infection: 2009 Update by the Infectious Diseases Society of America. 
Clin Infect Dis 20o9; 49: 1-45. [PubMed][CrossRef]

4. Helsedirektoratet. Retningslinjer for bruk av antibiotika i sykehus. Sepsis.

https://helsedirektoratet.no/retningslinjer/antibiotika-i-sykehus/seksjon?Tittel-

sepsis-1116\#sepsis,-mistanke-om-utgangspunkt-i-intravaskulært-kateter (10.12.2017).

5. Helsedirektoratet. Om sepsis - SIRS-kriterier - diagnostiske kriterier ved organsvikt - praktiske tiltak - antibiotikabehandling (forslag).

https://helsedirektoratet.no/retningslinjer/antibiotika-i-sykehus/seksjon?Tittel-

om-sepsis-sirs-kriterier-10361 (10.12.2017).

6. Mukherjee K, Chakrabart U, Mazumder P et al. Infected internal jugular vein thrombus in a case of infected arterio-venous fistula for dialysis access. Ann Vasc Dis 2014; 7:335-8. [PubMed][CrossRef]

7. Macari M, Panicek DM, Morris E. CT demonstration of infected SVC thrombus. Clin Imaging 1998; 22: 122-3. [PubMed][CrossRef]

8. McGee DC, Gould MK. Preventing complications of central venous catheterization. N Engl J Med 2003; 348: 1123-33. [PubMed][CrossRef]

9. Joffe HV, Goldhaber SZ. Upper-extremity deep vein thrombosis. Circulation 2002; 106:1874-80. [PubMed][CrossRef]

10. Flinterman LE, Van Der Meer FJ, Rosendaal FR et al. Current perspective of venous thrombosis in the upper extremity. J Thromb Haemost 2008; 6: 1262-6. [PubMed][CrossRef]

11. Mustafa S, Stein PD, Patel KC et al. Upper extremity deep venous thrombosis. Chest 2003; 123: 1953-6. [PubMed][CrossRef]

12. Tacke ], Adam G, Sliwka U et al. [Diagnosis of an infected thrombus of the inferior vena cava with ultrasound and computerized tomography]. Radiologe 1995; 35: 521-3. [PubMed]

13. Centers for Disease Control and Prevention (CDC). Vital signs: central line-associated blood stream infections-United States, 2001, 2008, and 2009. MMWR Morb Mortal Wkly Rep 2011; 60: 243-8.

[PubMed]

14. Fontela PS, Platt RW, Rocher I et al. Epidemiology of central line-associated bloodstream infections in Quebec intensive care units: a 6-year review. Am J Infect Control 2012; 40: 221-6. [PubMed][CrossRef]

15. Bouza E, Burillo A, Muñoz P. Catheter-related infections: diagnosis and intravascular treatment. Clin Microbiol Infect 2002; 8: 265-74. [PubMed][CrossRef]

16. McCann MT, Gilmore BF, Gorman SP. Staphylococcus epidermidis device-related infections: pathogenesis and clinical management. J Pharm Pharmacol 20o8; 60: 1551-71. [PubMed][CrossRef]

17. Klingenberg C. 1.4. Sentralvenøse katetre (CVK) til langtidsbruk. Pediatriveileder. https://www.helsebiblioteket.no/retningslinjer/pediatri/medisinske-prosedyrer/1.4-sentralvenøse-kat etre-cvk (10.12.2017).

Publisert: 20. februar 2019. Tidsskr Nor Legeforen. DOI: 10.4045/tidsskr.18.0157

Mottatt 15.2.2018, første revisjon innsendt 7.9.2018, godkjent 5.11.2018.

(C) Tidsskrift for Den norske legeforening 2020. Lastet ned fra tidsskriftet.no 